Gut, 1971, 12, 250-256

\title{
Pacesetter potential of the human gastroduodenal junction
}

\author{
H. L. DUThiE, N. K. KWONG, B. H. BROWN, AND G. E. WHitTAKER
}

From the Department of Surgery, University of Sheffield, and Regional Medical Physics Department, Sheffield

SUMMARY The pacesetter potential of the gastric antrum and proximal duodenum has been recorded in man by electrodes placed under the serosal coat of the gut. The typical $3 \mathrm{cycle} / \mathrm{min}$ of the stomach was found to be conducted across the pylorus into the first part of the duodenum at a rate $(2 \mathrm{~cm} / \mathrm{sec})$ about four times as fast as its conduction in the more proximal antrum $(0.5 \mathrm{~cm} / \mathrm{sec})$. A $3 \mathrm{cycle} / \mathrm{min}$ pacesetter potential could be detected as far distally in the duodenum as $10 \mathrm{~cm}$ from the pylorus.

Rhythmic electrical waves are present in the smooth muscle of the stomach and the duodenum at all times, even when motor activity is in abeyance. These electrical cycles are known as the pacesetter potentials. When motor activity occurs, another type of electrical activity, known as spike activity or action potentials, is present during the latter part of the pacesetter potential. It was generally held that the pacesetter from the antrum of the stomach does not pass beyond the pylorus in animals (Allen, Poole, and Code, 1964) and the pylorus was termed an 'electrical insulator' (Bass, Code, and Lambert, 1961). However, in animal experiments, some workers have detected antral activity in the pylorus itself (Llanfranchi, Barbara, and Bartolotti, 1968) and in the duodenum (Daniel, Carlow, Wachter, Sutherland, and Bogoch, 1959: Bortoff and Weg, 1965; Bortoff and Davis, 1968). We have studied this question in man, using implanted electrodes, and have found that the pacesetter potential is conducted from the stomach to the duodenum.

\section{Method}

Stainless steel electrodes, $\mathbf{0 . 2 5} \mathrm{mm}$ in diameter, were implanted just under the serosa of the distal $4 \mathrm{~cm}$ of the gastric antrum and the proximal $12 \mathrm{~cm}$ of the duodenum in 10 subjects, aged 28 to 52 years, undergoing cholecystectomy. The procedure was fully explained and informed consent was given by the patients. Two gastric electrodes were placed Received for publication 29 December 1970. respectively $4 \mathrm{~cm}$ (site 1) and $1.5 \mathrm{~cm}$ (site 2) from the pylorus (Fig. 1) which was identified by inspection and palpation. In the duodenum, one electrode was placed $1.5 \mathrm{~cm}$ from the pylorus (site 3) in all subjects. In one subject an additional electrode was introduced at site 6,10 to $12 \mathrm{~cm}$ from the pylorus near the level of the duodenal papilla. In the remaining four subjects, all four duodenal sites were

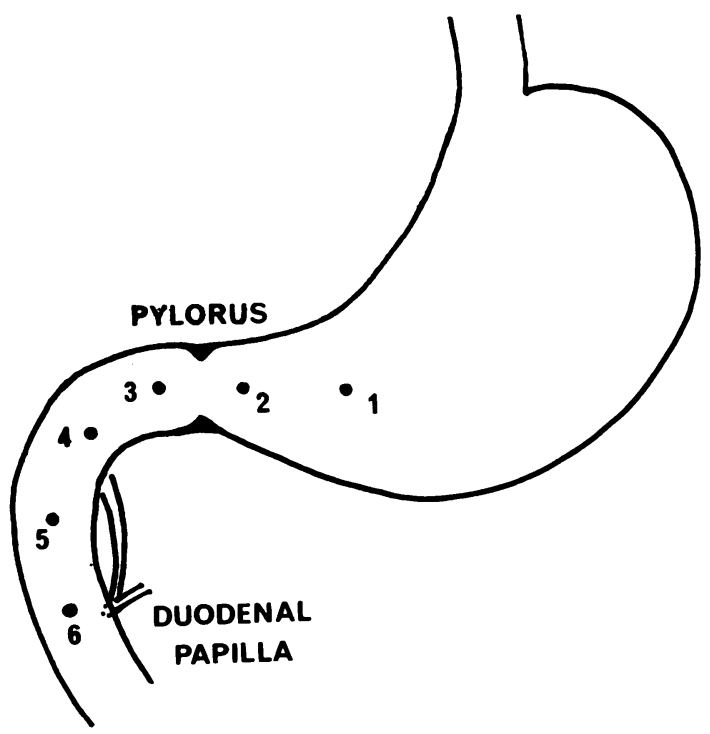

Fig. 1. Diagram showing the six sites of introduction of the electrodes under the serosal coat of the antrum and duodenum. 
utilized. Sites 4 and 5 were chosen so that the intervals between these four electrodes were approximately equal, ie, about $3.5 \mathrm{~cm}$. The electrodes were inserted after the gallbladder had been removed and the leads from them were brought out through the abdominal wall together with the surgical drain which is used, routinely, after this operation. The drain and the electrodes were removed together six days after surgery. No side effects were observed.

After an overnight fast, monopolar recordings were made, for periods of one to two hours, from three to six days postoperatively. The indifferent electrode was placed on the skin over the right iliac fossa. Signals from the electrodes were amplified on an $\mathrm{A} / \mathrm{C}$ amplifier, with a frequency response from 0.02 to $1.0 \mathrm{~K} \mathrm{H}_{2}$. The records were displayed on an ultraviolet recorder and stored on magnetic tape for computer analysis. Parallel outputs were fed to a high pass and a low pass electronic filter in some records to emphasize selected frequency responses for special attention. Useful records were obtained from all 10 subjects.

The frequency and amplitude of the electrical waves were measured, and where possible by inspection of the records, conduction times of the impulses between adjacent electrodes were calculated. More

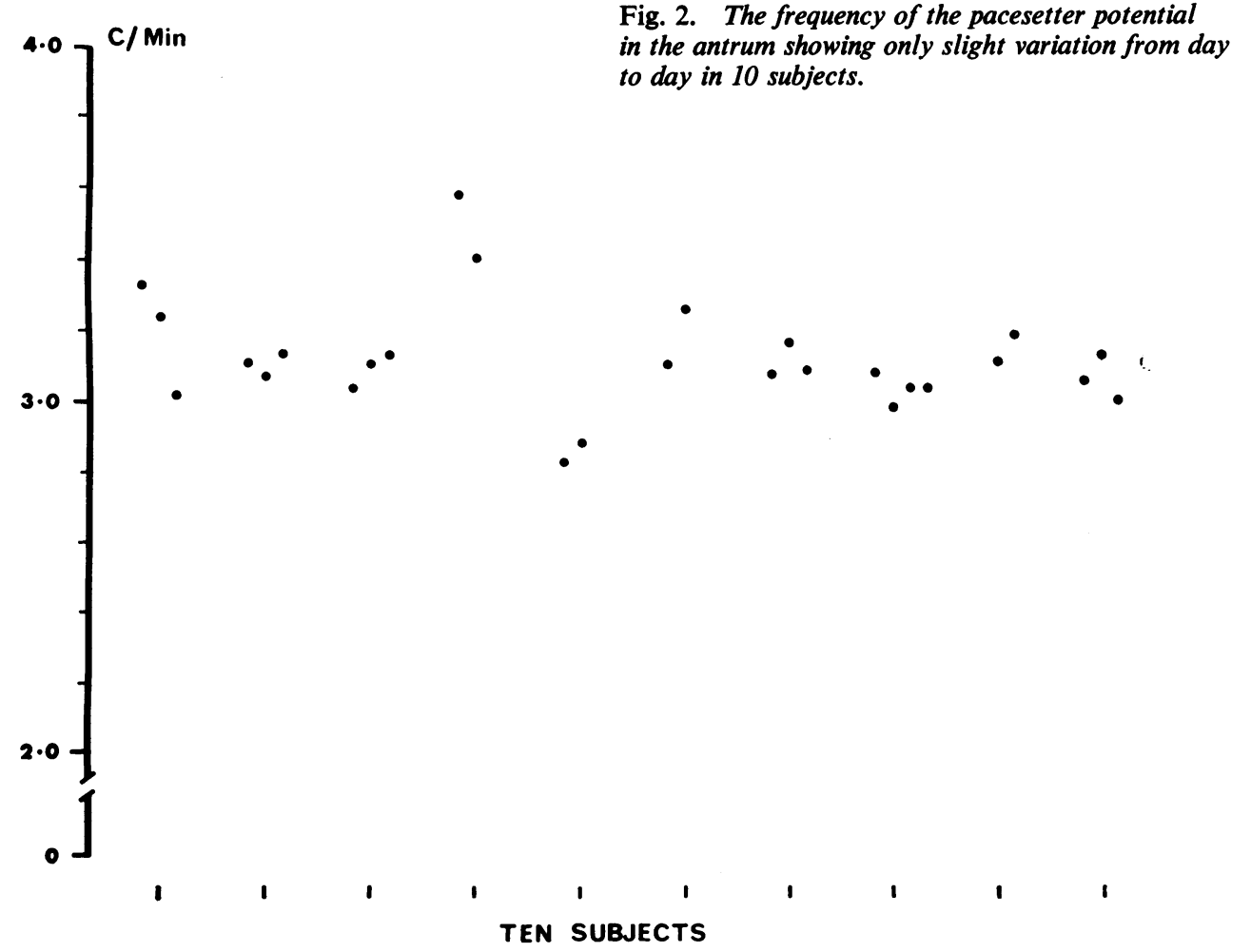

complex analysis by computer methods will be reported in a subsequent paper (Brown, Whittaker, Franks, Kwong, and Duthie, 1970).

All subjects had at least one test in which no stimulus was given. Test substances were administered in another 11 tests which began with a 30-min resting record. Ingestion of fluid meals at a temperature of $37^{\circ} \mathrm{C}$ was studied on eight occasions. The fluid meal consisted of $250 \mathrm{ml}$ of water in two tests, $250 \mathrm{ml}$ of 200 milliosmole/litre solution of sodium citrate in three, and $250 \mathrm{ml}$ of oleate suspension $(19 \mathrm{~g} / \mathrm{l}$ trisodium citrate and 10 millimoles oleic acid suspended in $0.5 \%$ Tween 80 ) in three. In the remaining three tests, $10 \mathrm{mg}$ morphine sulphate was given intravenously after the 30-min resting recording during which a control injection of saline was given.

\section{Results}

The frequency of the pacesetter potential in the antrum was stable during the two hours of a recording made at rest, varying by a maximum of $5 \%$ in consecutive 30 -min periods of recording. In addition, it varied little from day to day (Fig. 2). The waveform in the stomach (Fig. 3) was similar

Fig. 2. The frequency of the pacesetter potential in the antrum showing only slight variation from day to day in 10 subjects. 


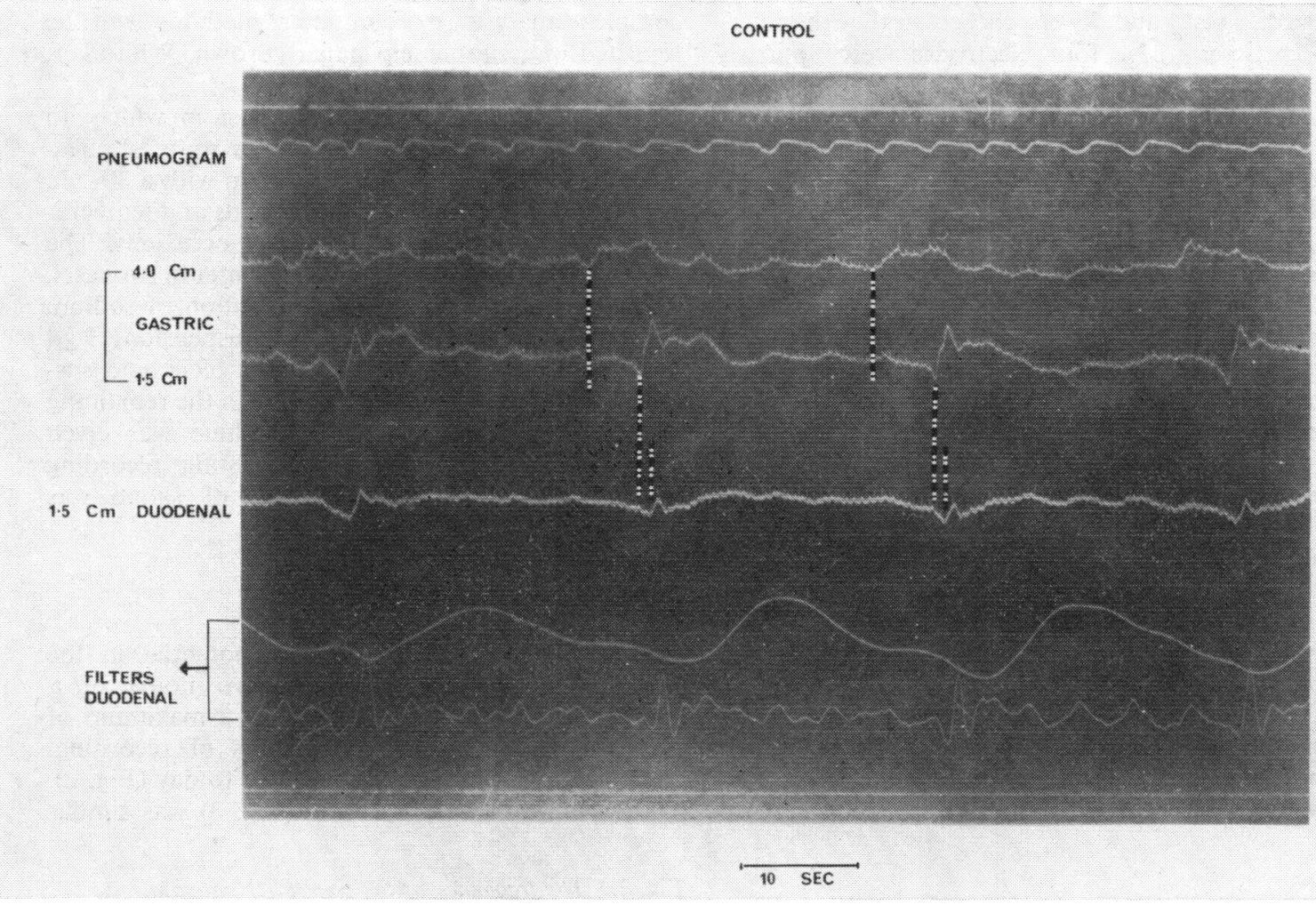

Fig. 3. Tracing from antrum (sites 1 and 2) and duodenum (site 3) showing 3 cycle/min activity and conduction of the electrical impulse.

to that obtained from electrodes sucked on the mucosa (Kwong, Brown, Whittaker, and Duthie, 1970 ) and the mean frequency $3 \cdot 12 \pm 0.05$ (1 SE) cycles/min was also similar. The amplitude of the fast component of the pacesetter potential at $1.5 \mathrm{~cm}$ from the pylorus had a mean value of $2 \cdot 27 \pm 0 \cdot 30$ $\mathrm{mV}$ (1 SE). Action potentials were seen only occasionally in the tracings from the unstimulated stomach and in the duodenum.

From 10 to $12 \mathrm{~cm}$ distal to the pylorus, the frequency of the pacesetter potential in the duodenum was about $12 \mathrm{cycle} / \mathrm{min}$ (mean $11.74 \pm 0.13$ (1 SE) c/min).

In the five subjects with electrodes in this region, the frequency of the pacesetter potential was stable from day to day (Fig. 4). In the more proximal duodenum, and especially in the most proximal 4 to $5 \mathrm{~cm}$, the predominant pattern showed 3 cycle/ $\mathrm{min}$ as in the antrum, superimposed occasionally on the $12 \mathrm{cycle} / \mathrm{min}$ (Figs. 3 and 5). No direct relationship could be established between the frequencies of the gastric ( $3 \mathrm{cycle} / \mathrm{min})$ and duodenal
(12 cycle/min) intrinsic activities. The conduction velocity of the electrical waves in the antrum between 4.0 and $1.5 \mathrm{~cm}$ from the pylorus was about $0.5 \mathrm{~cm} /$ sec (mean $0.60 \pm 0.10$ (1 SE). Across the pyloric region, the conduction was four times as fast at about $2 \mathrm{~cm} / \mathrm{sec}$ (mean $2.06 \pm 0.46(1 \mathrm{SE}) \mathrm{cm} / \mathrm{sec}$. Beyond $2 \mathrm{~cm}$ from the pylorus the identification of the initial part of the 3-cycle pacesetter potential was less definite and estimation of an accurate conduction time was not possible. Neither was it possible to estimate conduction times for the $12 \mathrm{cycle} / \mathrm{min}$ pacesetter potential in the more distal duodenum by inspection of the records.

Ingestion of water (Fig. 6a), citrate (Fig. 6b), or oleate (Fig. 6c) significantly slowed the frequency of the pacesetter potential in the antrum for $10 \mathrm{~min}$ with recovery to resting levels after ingestion in all tests, and a later increase after the latter two meals (Figs. $6 \mathrm{~b}$ and c). They had no effect on the amplitude of the fast component of the pacesetter potential. The intravenous injection of $10 \mathrm{mg}$ morphine sulphate produced no change 


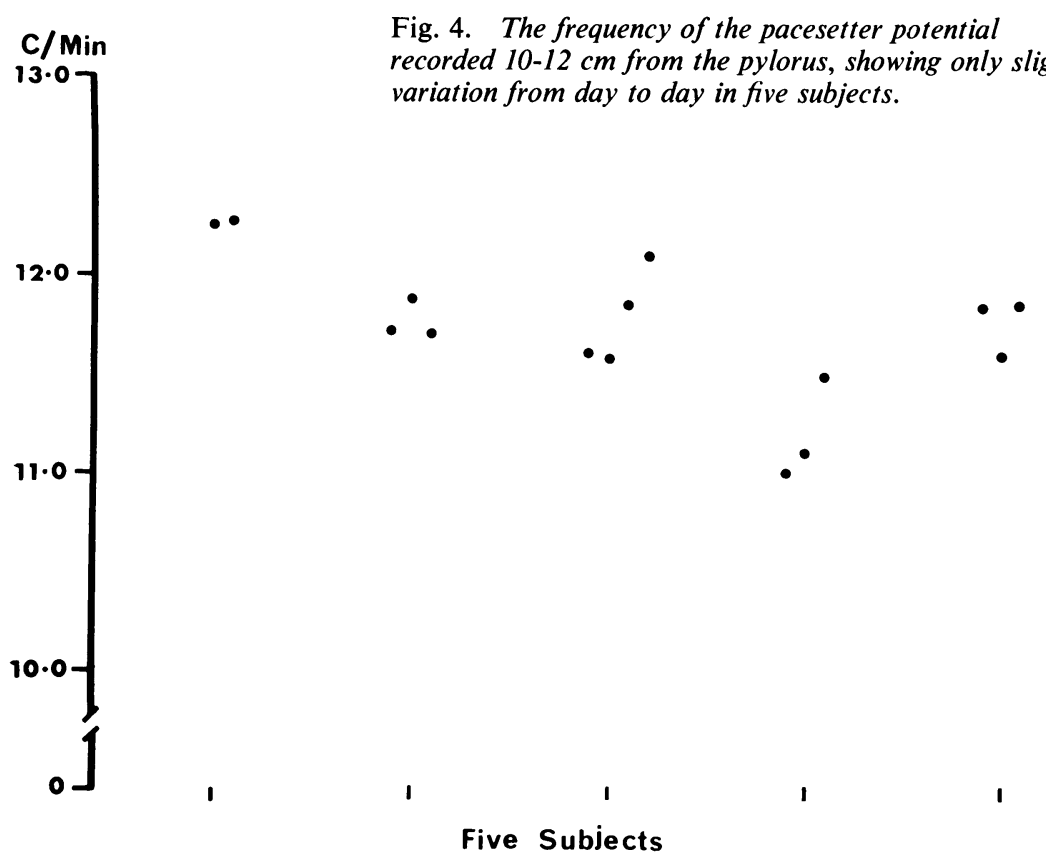

Fig. 5. Tracing from the antrum (site 2) and the duodenum (site 3) showing 2 cycle/min rhythm superimposed on 3 cycle/min at site 3 after $10 \mathrm{mg}$ morphine sulphate had been given intravenously. 
Mean $\pm 2 S E$

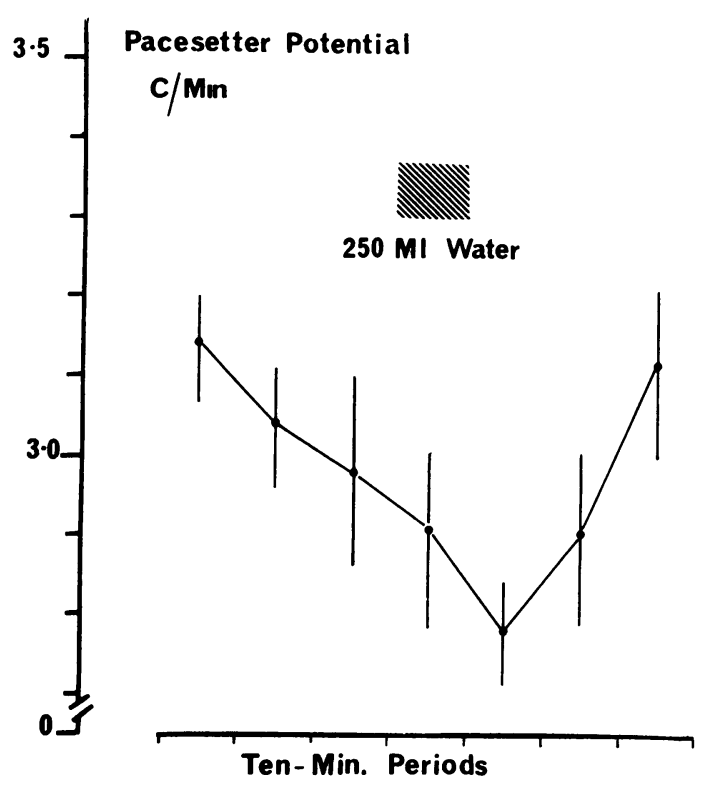

Fig. 6. Effect of ingestion of fluid meals on the frequency of the pacesetter potential of the antrum: (a) $250 \mathrm{ml}$ water, (b) $250 \mathrm{ml}$ citrate solution.

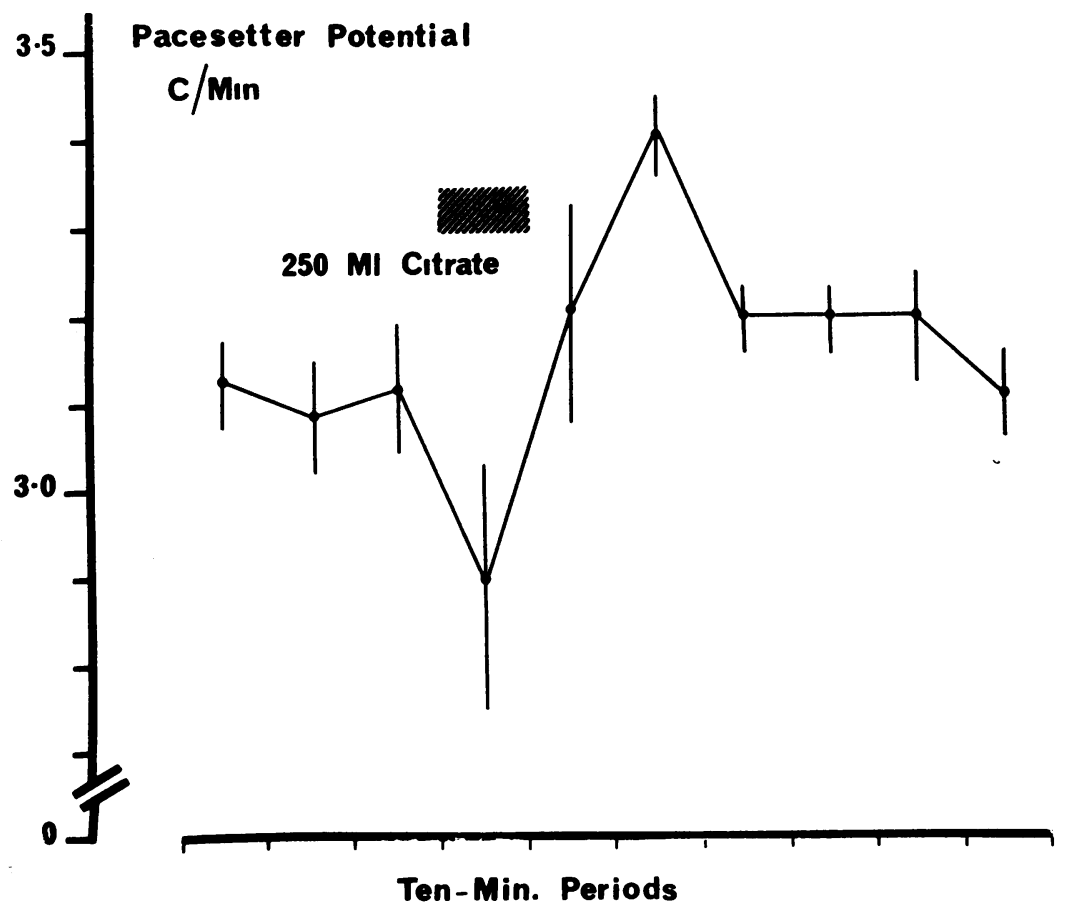

Fig. 6b 
Mean \pm 2 SE

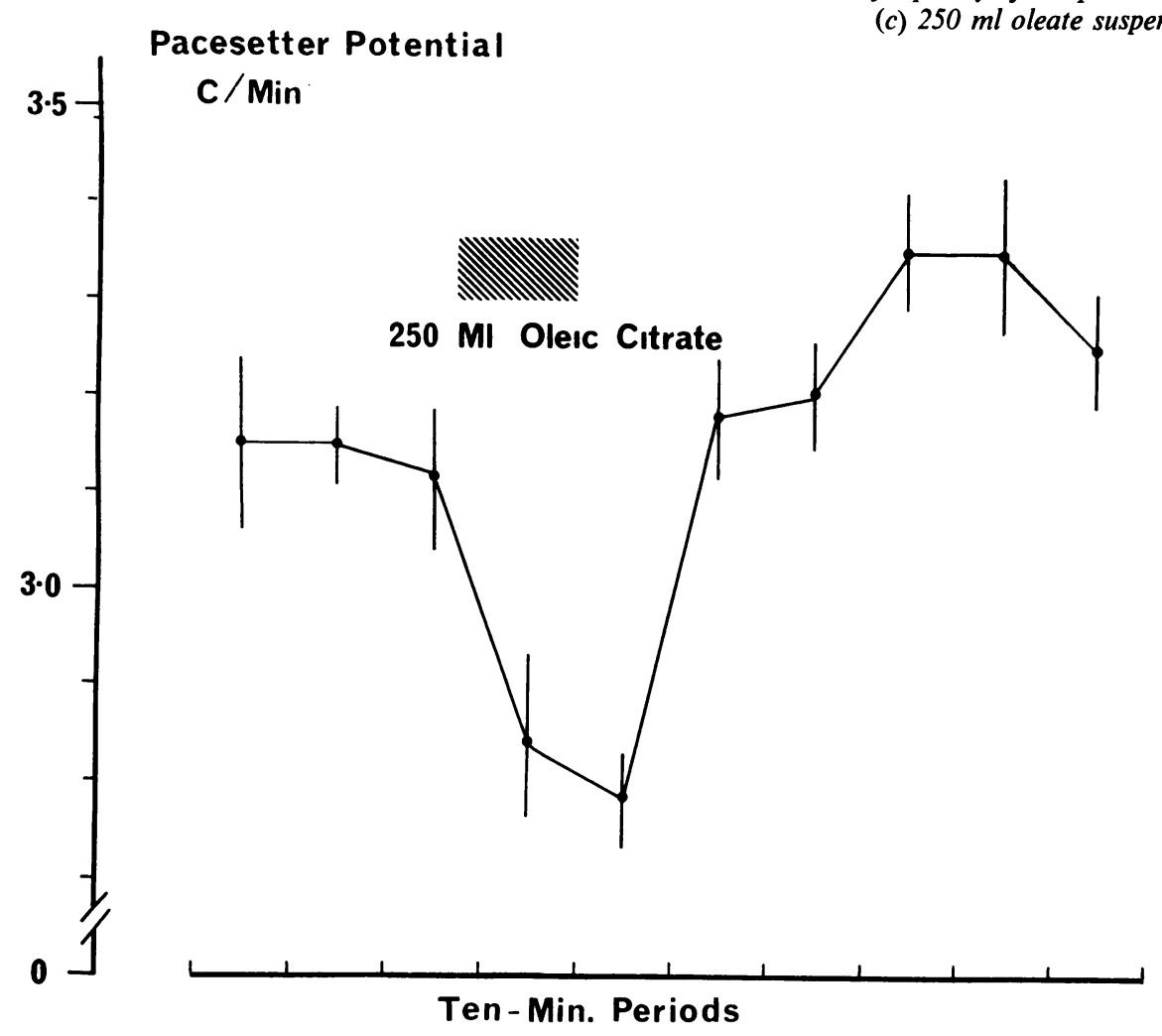

Fig. 6c. Effect of ingestion of fluid meals on the frequency of the pacesetter potential of the antrum: (c) $250 \mathrm{ml}$ oleate suspension.

Fig. 7. Tracing from antrum (site 2) showing action potentials superimposed on the pacesetter potential following the injection of $10 \mathrm{mg}$ morphine sulphate intravenously. 
in the frequency and amplitude of the pacesetter potential in the stomach but increased the amplitude of the $3 \mathrm{cycle} / \mathrm{min}$ waves in the duodenum.

It was also followed by a more definite appearance of the $12 \mathrm{cycle} / \mathrm{min}$ pacesetter potential at the more proximal duodenal electrodes within $1.5 \mathrm{~cm}$ of the pylorus (Fig. 5). The incidence of action potentials was increased in both the gastric and duodenal records (Fig. 7).

\section{Discussion}

The conduction of the pacesetter potential at a frequency of 3 cycles/min from the antrum across the pylorus into the proximal duodenum in man supports the findings of in vivo studies in animals (Bortoff and Davis, 1968). It seems logical that, since the antrum and the duodenum are coordinated for gastric emptying (Thomas, 1957), electrical impulses should pass from one to the other to assist in the coordination. We have provided no evidence as to the route of conduction but it is possible that the small number of longitudinal muscle fibres continuing from the antrum across the pylorus could provide a pathway.

It must be remembered that these recordings had to be made in the first few days after surgery before the removal of the surgical drain, so that we were not able to wait for two to three weeks before making recordings, as is the custom with similar implants in animals. However, it would appear that the recordings have not been influenced by this shorter postoperative interval for the following reasons:

The pacesetter potential had the same frequency as previously reported in man both for the antrum (Nelsen and Kohatsu, 1968; Monges, Salducci, and Roman, 1969; Kwong et al, 1970) and for the duodenum (Christensen, Clifton, and Schedl, 1966; Monges and Salducci, 1970).

The slowing effect of meals on the frequency of the pacesetter potential was similar to that found in man (Nelsen and Kohatsu, 1968) and dogs (Kelly, Code, and Elveback, 1969).

The significance of these findings in the control of gastroduodenal motor activity is speculative. Cor- relations between bursts of duodenal action potentials and the antral pacesetter potential have been found in dogs after feeding (Allen et al, 1964), suggesting coordination of activity but no conduction of the antral pacesetter potential itself was observed across the pylorus. In our work the action potentials in the duodenum were not seen sufficiently often to permit estimation of such a correlation between action potentials and the frequency of the gastric pacesetter potentials. However, although we demonstrated that the 3 cycle/min rhythm of the antrum could be found in the duodenum, we were unable to detect any relationship between this frequency and the $12 \mathrm{cycle} / \mathrm{min}$ frequency of the duodenum itself.

References

Allen, G. L., Poole, E. W., and Code, C. F. (1964). Relationships between electrical activities of antrum and duodenum. Amer. J. Physiol., 207, 906-910.

Bass, P., Code, C. F., and Lambert, E. H. (1961). Electrical activity of gastroduodenal junction. Amer. J. Physiol., 201, 587-592.

Bortoff, A., and Davis, R. S. (1968). Myogenic transmission of antral slow waves across the gastroduodenal junction in situ. Amer.J. Physiol., 215, 889-897.

Bortoff, A., and Weg, N. (1965). Transmission of electrical activity through the gastroduodenal junction. Amer. J. Physiol., 208, 531-536.

Brown, B. H., Whittaker, G. E., Franks, C. I., Kwong, N. K., and Duthie, H. L. (1970). Computer analysis and simulation of human gastroduodenal electrical activity. Submitted to Med. Biol. Eng.

Christensen, J., Clifton, J. A., and Schedl, H. P. (1966). Variations in the frequency of the human duodenal basic electrical rhythm in health and disease. Gastroenterology, 51, 200-206.

Daniel, E. E., Carlow, D. R., Wachter, B. T., Sutherland, W. H., and Bogoch, A. (1959). Electrical activity of the small intestine. Gastroenterology, 37, 268-281.

Kelly, K. A., Code, C. F., and Elveback, L. R. (1969). Patterns of canine gastric electrical activity. Amer. J. Physiol., 217, 461-470.

Kwong, N. K., Brown, B. H., Whittaker, G. E., and Duthie, H. L. (1970). Response of the electrical activity and acid secretion of the human stomach to pentagastrin and histamine stimulation. Scand. J. Gastroent., in the press.

Llanfranchi, G. A., Barbara, L., and Bortolotti, M. (1968). Attività elettrica del giunto gastro-duódenale e suoi rapport: con l'attivilà elettrica dell' antro e del duodeno.

Monges, H., and Salducci, J. (1970). Étude électromyographique de la motricité duodenale chez l'homme normal. Arch. Mal. Appar. dig., 59, 19-28.

Monges, H., Sulducci, J., and Roman, C. (1969). Etude électromyographique de la motricité gastrique chez l'homme normal. Arch. Mal. Apparat. dig., 59, 19-28.

Nelsen, T. S., and Kohatsu, S. (1968). Clinical electrogastrography and its relationship to gastric surgery. Amer. J. Surg., 116, 215. 222.

Thomas, J. E. (1957). Mechanics and regulation of gastric emptying. Physiol. Rev., 37, 453-474. 